\title{
Rancang Bangun Prototipe Sistem Smart Parking Berbasis Iot Menggunakan Node Mcu Esp8266
}

\author{
Arif Wihandanto ${ }^{1}$, Arif Johar Taufiq ${ }^{2}$, Wakhyu Dwiono ${ }^{3}$ \\ Program Studi S1 Teknik Elektro, Universitas Muhammadiyah Purwokerto \\ Fakultas Teknik dan Sains, Universitas Muhammadiyah Purwokerto \\ Email : arifwihandanto@gmail.com¹, arifjt@gmail.com², wakhyudwi@gmail.com
}

\begin{abstract}
Abstrak - Salah satu perkembangan teknologi dalam bidang transportasi salah satunya adalah sistem pelayanan parkir. Sistem pelayanan parkir saat ini telah banyak menggunakan sistem otomatis dalam pengoperasiannya, namun calon pengguna parkir masih terkendala dalam mengetahui informasi ketersediaan ruang parkir, tidak hanya itu pengguna parkir tidak jarang harus menghabiskan waktu untuk mencari ruang parkir yang harus mereka tuju. Untuk mengatasi masalah in perlu sebuah solusi untuk membuat sistem parkir yang dapat memberikan informasi terkait ketersediaan ruang parkir, dan juga dapat mengarahkan pengguna parkir untuk menuju ruang parkir yang tersedia. Pada sistem smart parking ini pengujian dilakukan dengan simulasi menggunakan miniatur parkir dimana informasi ketersediaan ruang parkir, dan petunjuk ruang parkir yang harus dituju ditampilkan pada modul penampil P10, dan dapat diakses melalui server lokal dengan wireless, yang penandaan parkirnya ditandai menggunakan kartu RFID. Hasil penelitian pada sistem smart parking ini, sistem ini tidak hanya mengelola sistem keamanan, tapi juga mengelola tata letak penempatan atau pengalamatan kendaraan pada slot-slot parkir yang tersedia, tidak hanya itu informasi ketersediaan slot parkir juga dapat dilihat secara offline pada modul penampil p10, dan juga dapat dimonitoring secara online melalu server lokal.
\end{abstract}

Kata Kunci- Teknologi transportasi, Sistem parker, Prototipe,

Rfid

Monitoring

\section{PENDAhUluan}

Salah satu perkembangan teknologi dalam bidang transportasi salah satunya adalah sistem layanan parkir. Sebagai salah satu layanan publik, proses parkir harus dikelola dengan baik. Pengelolaan proses parkir yang baik harus memperhatikan segi keamanan dan kenyamanan penggunanya. Selain itu setiap data proses parkir menjadi hal yang penting untuk dikelola[1]. Sistem Parkir Otomatis adalah sistem yang mengotomatiskan parkir mobil di mana kita tidak perlu membuang waktu untuk mencari tempat parkir mobil yang kosong. Hanya dengan sentuhan tag RFID maka mobil kita akan diparkir secara otomatis di tempat yang telah kita tentukan sebelumnya[2]. Salah satu indikator pengelolaan sistem parkir yang baik adalah proses pelayanan yang lancar dan keamanan parkir yang bagus. Sistem parkir dengan menggunakan Radio Frequency Identification Digital (RFID) mampu memberikan kedua hal yang dibutuhkan oleh pengguna jasa parkir aman dan efisien[3]. Teknologi RFID memiliki beberapa keunggulan seperti pemindaian cepat, daya tahan, penggunaan berulang, penetrabilitas, pembacaan tanpa penghalang, kapasitas memori yang besar dan keamanan yang tinggi[4]. Penerapan teknologi RFID ini dapat memberi kemudahan pada suatu organisasi untuk mengembangkan efisiensi pekerjaan dan kualitas layanan menjadi lebih baik[5].

Sistem smart parking pernah diwujudkan dalam penelitian menggunakan Arduino UNO, RFID, I2C LCD, dan menggunakan dua buah Motor servo dengan metode pemberian izin akses pada kartu RFID dan pembatasan bagi pengguna parkir[6], kemudian pegembangan sistem parkir selanjutnya pernah diteliti menggunakan NodeMCU ESP8266 yang dipadukan dengan sensor ultrasonic HCSR-04, dan monitoring menggunakan website dengan menggunakan metode pelacakan slot parkir yang kosong, dengan menanamkan sensor ultrasonic pada setiap slotnya untuk menyatakan kondisi slot parkir[7], Penelitian lain pengembangan sistem parkir dengan sistem rekomendasi lokasi parkir dibuat dengan menggunakan Arduino Mega2560, dengan sesnsor di tiap slotnya dan output berupa print thermal dan tampilan 7 segment, Informasi terkait lokasi parkir yang direkomendasikan diprint pada tiket ketika pertama masuk yang mana sudah terintegrasi pada tiap sensor pada tiap slot untuk merekomendasikan slot patkir[8].

Penelitian selanjutnya pernah dibuat menggunakan sensor LDR, mikrokontroler AT89S51, rangkaian motor stepper dan display seven segment. Prinsip kerja sistem ini adalah kesepuluh rangkaian sensor LDR digunakan sebagai saklar tak terlihat pada masing-masing tempat parkir yang berfungsi untuk menentukan nomor tempat parkir yang kosong dan kedua sensor LDR lainnya pada pintu masuk dan pintu keluar, untuk membuka portal pintu masuk dan keluar area parkir yang digerakkan oleh motor stepper[9], Penelitian lain pernah dilakukan dengan menggunakan sistem reservasi dan pemantauan parkir pada lokasi kampus menggunakan NFC dan konsep IoT. NFC digunakan untuk melakukan konfirmasi dari kode pemesanan yang telah dihasilkan oleh sistem. Pada lokasi parkir, sensor jarak ultrasonik dipasang untuk mendeteksi ketersediaan parkir[10],

Berdasarkan latar belakang dan hasil penelitian di atas dibuat alat "Rancang bangun prototipe sistem smart parking berbasis IoT menggunakan node mcu esp8266" dengan metode penghitungan dan pengalamatan slot parkir menggunakan sensor RFID, yang mana hasil perhitungan dan pengalamatan tersebut nantinya ditampilkan pada sebuah display berupa Modul penampil P10 dan juga dapat dilihat atau dimonitoring menggunakan wireless dengan server lokal.

\section{BAHAN DAN METODE}

\section{A. Flowchart Sistem}

Metode yang digunakan pada sistem parkir ini yaitu dengan mengarahkan atau mengalamatkan calon pengguna parkir pada slot parkir terdekat yang mana nantinya slot parkir akan terisi secara berurutan dari slot terkecil yang kosong, Sehingga slot yang 
kosong dan yang terisi tetep dapat dipetakan. metode ini digunakan untuk mengganti fungsi penempatan sensor pada tiap slot parkir, dengan menggunakan kartu RFID dimana setiap kartu yang masuk akan terdata dan akan menyimpan alamat masing masing slot parkir yang dialamatkan. Diagram flowchart berikut berfungsi untuk membuat alur jalannya sistem yang dibuat, perancangan ini juga digunakan sebagai urutan dalam berjalannnya sistem smart parking ini. Perancangan seperti Gambar 1 berikut.

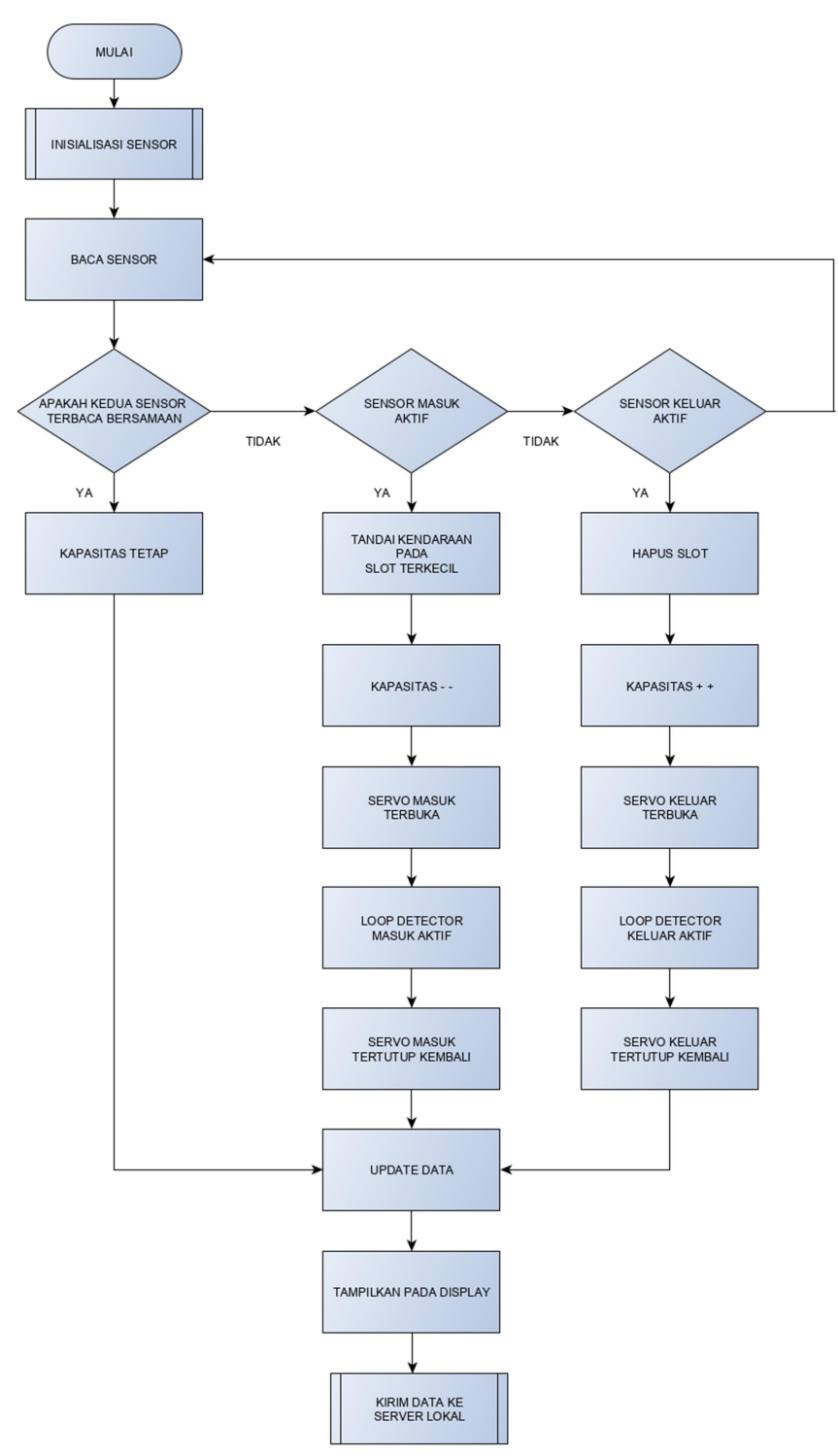

[1]

Gambar 1. Flowchart system

\section{B. Perancangan Prototipe}

Prototipe ini diaplikasikan dengan membuat miniatur, untuk mensimulasikan fungsi sistem smart pakring ini pada keadaan sebenarnya, desain prototipe ini dapat dilihat seperti pada gambar 2 .

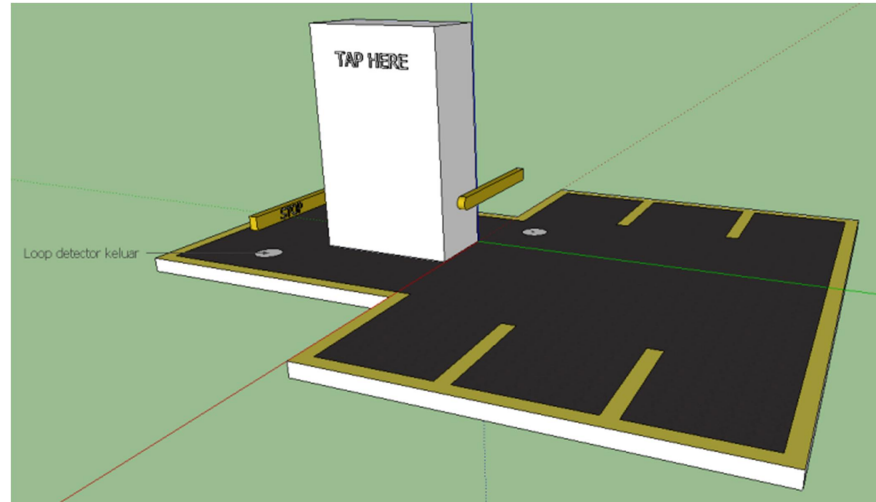

[2] Gambar 2. Desain prototipe

\section{Pengujian Prototipe Sistem Smart Parking}

Pengujian Pengalamatan ini dilakukan dengan menempelkan kartu RFID dengan RFID Reader, pengujian ini juga dilakukan untuk menguji izin kartu, ketika kartu ditap, kartu yang memiliki izin akses akan menampilkan alamat slot yang harus dituju pada display modul P10. Pengujian ini dilakukan bertahap, yang pertama adalah pengujian pengalamatan secara berurutan dari slot 1-6, dan pengujian pengalamatan apa bila terdapat slot yang kosong.

\section{Hasil dan Pembahasan}

Setelah dilakukan pembuatan alat dan pengujian terhadap seluruh rangkaian maka diperoleh hasil berupa suatu rancang bangun prototipe sistem smart parking berbasis IoT menggunakan NodeMCU Esp8266. Hasil pembuatan prototipe dapat dilihat pada gambar 3.

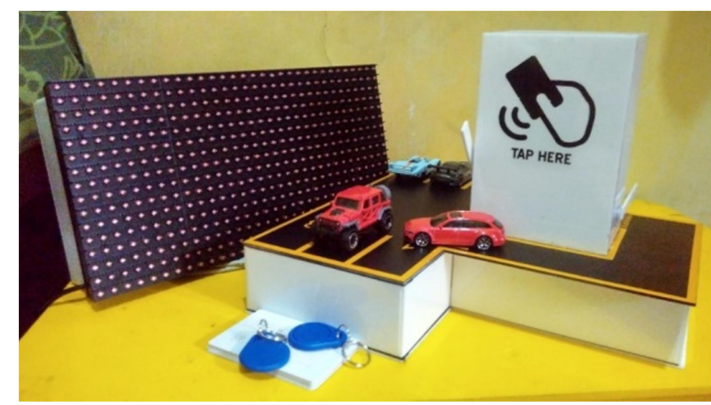

[3] Gambar 3. Prototipe Sistem Smart Parking

\section{A. Pengujian Pengalamatan Slot Parkir}

Pengujian pengalamatan ini dilakukan dengan 2 pengujian yaitu diuji secara berurutan dan diuji apa bila terdapat slot yang kosong.

a. Pengujian pengalamatan secara berurutan

Pengujian ini dilakukan secara berurutan, dengan kondisi keadaan slot parkir dalam keadaan benar-benar kosong, pengujian ini sesuai, Karena status pada display dan pengalamatan slot yang ditampilkan sudah sesuai dengan yang diharapkan, hasil pengujian pengalamatan secara berurutan dapat dilihat seperti pada tabel 1 .

[4] Tabel 1. Pengujian Pengalamatan Secara Berurutan 


\begin{tabular}{cccccc}
\hline No & ID & $\begin{array}{c}\text { Slot yang } \\
\text { dituju }\end{array}$ & $\begin{array}{c}\text { Display } \\
\text { P10 }\end{array}$ & $\begin{array}{c}\text { Status } \\
\text { Slot }\end{array}$ & Keterangan \\
\hline 1 & 1 & 1 & SLOT 1 & $\begin{array}{c}\text { Tersedia } \\
5\end{array}$ & SESUAI \\
2 & 2 & 2 & SLOT 2 & $\begin{array}{c}\text { Tersedia } \\
4\end{array}$ & SESUAI \\
3 & 3 & 3 & SLOT 3 & $\begin{array}{c}\text { Tersedia } \\
3\end{array}$ & SESUAI \\
4 & 4 & 4 & SLOT 4 & $\begin{array}{c}\text { Tersedia } \\
2\end{array}$ & SESUAI \\
5 & 5 & 5 & SLOT 5 & $\begin{array}{c}\text { Tersedia } \\
1\end{array}$ & SESUAI \\
6 & 6 & 6 & SLOT6 & $\begin{array}{c}\text { Tersedia } \\
0\end{array}$ & SESUAI \\
\hline
\end{tabular}

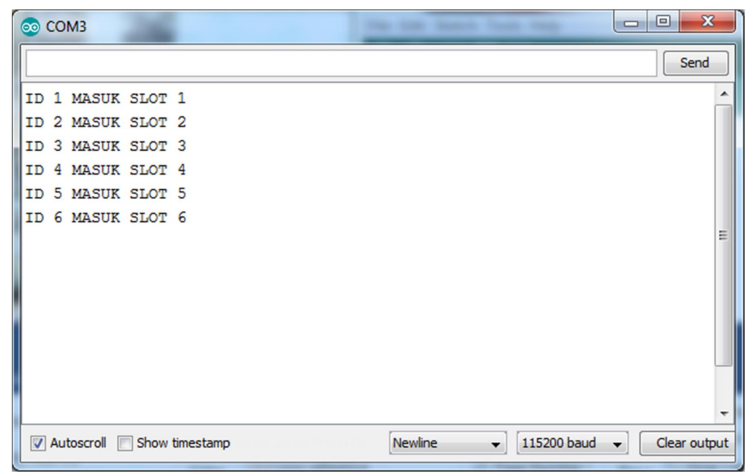

[5] Gambar 4. Tampilan pada serial monitor

b. Pengujian Ketika Terdapat Slot yang kosong

Pada simulasi pengujian ini, disimulasikan pada keadaan awal hanya terdapat 3 slot yang kosong diantaranya yaitu Slot $3,{ }^{3}$ Slot 4 dan Slot 6, yang mana kartu selanjutnya yang akan parkir, akan dialamatkan menuju secara berurutan dari yang kecil terlebih dahulu, yaitu Slot 3, Slot 4 dan Slot 6, yang nantinya ditampilkan5 pada display modul P10. Hasil pengujian ketika terdapat slot kosong dapat dilihat pada table 2

[6] Tabel 2. Pengujian 2 Pada Kondisi Awal

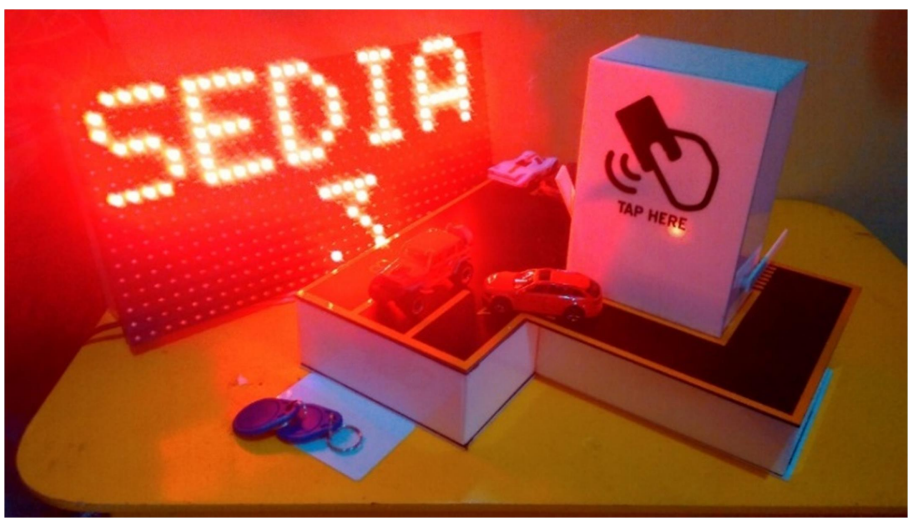

[8] Gambar 5. Tampilan pada display

Perubahan slot setelah dialamatkan dapat dilihat pada tabel 3

[9] Tabel 3. Pengujian 2 Setelah Dialamatkan

\begin{tabular}{|c|c|c|c|c|c|c|c|c|c|c|}
\hline \multirow{2}{*}{$\begin{array}{l}\mathbf{N} \\
\mathbf{0} \\
\text {. }\end{array}$} & \multirow{2}{*}{$\begin{array}{l}\text { Ka } \\
\text { rtu }\end{array}$} & \multirow{2}{*}{$\begin{array}{c}\text { Slo } \\
\text { t } \\
\text { ya } \\
\text { ng } \\
\text { dit } \\
\text { uju }\end{array}$} & \multirow[b]{2}{*}{1} & \multirow[b]{2}{*}{2} & \multicolumn{3}{|c|}{ Status slot } & \multirow[b]{2}{*}{6} & \multirow{2}{*}{$\begin{array}{l}\text { Status } \\
\text { Slot }\end{array}$} & \multirow{2}{*}{$\begin{array}{c}\text { Keteran } \\
\text { gan }\end{array}$} \\
\hline & & & & & 3 & 4 & 5 & & & \\
\hline 1 & 1 & $\begin{array}{l}\text { Slo } \\
\text { t } 1\end{array}$ & $\begin{array}{l}\mathrm{Te} \\
\text { risi }\end{array}$ & & & & & & $\begin{array}{l}\text { Tersed } \\
\text { ia } 5\end{array}$ & - \\
\hline 2 & 2 & $\begin{array}{l}\text { Slo } \\
\text { t } 2\end{array}$ & & $\begin{array}{l}\mathrm{Te} \\
\text { risi }\end{array}$ & & & & & $\begin{array}{c}\text { Tersed } \\
\text { ia } 4\end{array}$ & - \\
\hline & 5 & $\begin{array}{l}\text { Slo } \\
\text { t } 5\end{array}$ & & & & & $\begin{array}{l}\mathrm{Te} \\
\text { risi }\end{array}$ & & $\begin{array}{l}\text { Tersed } \\
\text { ia } 3\end{array}$ & - \\
\hline & 3 & $\begin{array}{l}\text { Slo } \\
\text { t } 3\end{array}$ & & & $\begin{array}{l}\mathrm{Te} \\
\text { risi }\end{array}$ & & & & $\begin{array}{l}\text { Tersed } \\
\text { ia } 2\end{array}$ & $\underset{\text { I }}{\text { SESUA }}$ \\
\hline & 4 & $\begin{array}{l}\text { Slo } \\
\text { t } 4\end{array}$ & & & & $\begin{array}{l}\mathrm{Te} \\
\text { risi }\end{array}$ & & & $\begin{array}{l}\text { Tersed } \\
\text { ia } 1\end{array}$ & $\underset{\text { I }}{\text { SESUA }}$ \\
\hline 6 & 6 & $\begin{array}{l}\text { Slo } \\
\text { t } 6 \\
\end{array}$ & & & & & & $\begin{array}{l}\mathrm{Te} \\
\text { risi }\end{array}$ & $\begin{array}{c}\text { Tersed } \\
\text { ia } 0 \\
\end{array}$ & $\begin{array}{c}\text { SESUA } \\
\text { I }\end{array}$ \\
\hline
\end{tabular}

\section{[7]}

\begin{tabular}{ccccccccc}
\hline $\mathbf{N}$ & $\mathbf{I}$ & \multicolumn{5}{c}{ Status slot } & Status Slot \\
$\mathbf{0 .}$ & $\mathbf{D}$ & $\mathbf{1}$ & $\mathbf{2}$ & $\mathbf{3}$ & $\mathbf{4}$ & $\mathbf{5}$ & $\mathbf{6}$ & \\
\hline $\mathbf{1}$ & 1 & $\begin{array}{c}\text { Teri } \\
\text { si }\end{array}$ & & & & & & Tersedia 5 \\
$\mathbf{2}$ & 2 & & $\begin{array}{c}\text { Teri } \\
\text { si }\end{array}$ & & & & & Tersedia 4 \\
$\mathbf{3}$ & 5 & & & & & Teri & Tersedia 3 \\
$\mathbf{4}$ & - & & & Koso & & & & Tersedia 2 \\
$\mathbf{5}$ & - & & & ng & Koso & & & Tersedia 1 \\
$\mathbf{6}$ & - & & & & ng & & Koson & Tersedia 0 \\
\hline
\end{tabular}

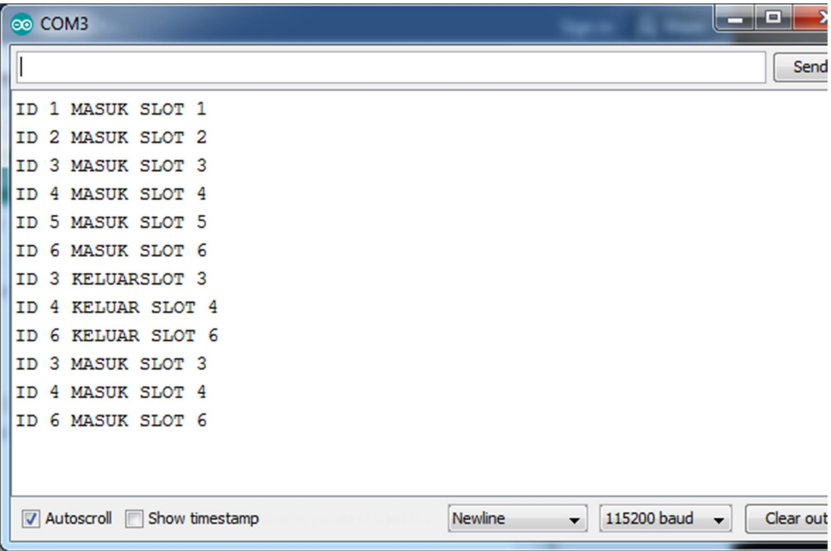

[10] Gambar 6. Tampilan serial monitor ketika slot yang kosong berubah terisi 


\section{B. Pengujian Sensor Loop Detector}

Pengujian ini dilakukan, dengan membuat lilitan induktansi loop detector, sensor ini dibuat dengan luas $50 \mathrm{~cm} \mathrm{x}$ $35 \mathrm{~cm}$, dengan membuat lilitan dari 1 lilitan hingga 5 lilitan mengikuti luas sensor, respon induktansi dengan jarak yang ideal $\geq 24 \mathrm{~cm}$ yang akan dijadikan data tunggal dan diaplikasikan pada prototipe ini. Hasil pengujian induktansi dari lilitan 1 hingga lilitan 4, seperti pada gambar 7. Contoh pengujian sensor loop detector dapat dilihat pada gambar berikut.

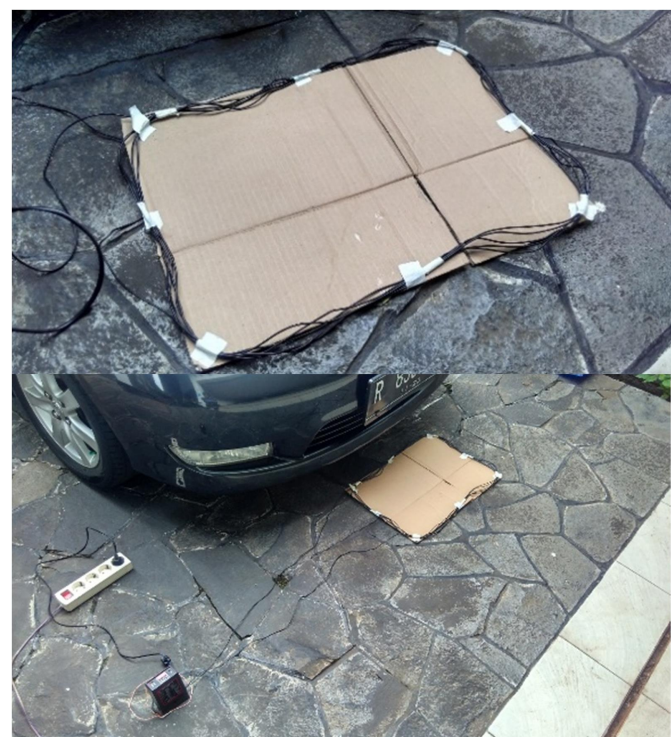

[11] Gambar 7. Belitan sensor loop detector(atas) dan contoh pengujian sensor (bawah)

Untuk menentukan nilai induktansi pada sensor loop detector digunakan persamaan(1) seperti rumus berikut.

$L=$

$\mu_{0} \frac{N^{2} \cdot A}{l}$

\section{Dimana:}

$$
\begin{array}{ll}
\mathrm{L}=\text { induktasni }(\mathrm{H}) & \mathrm{N}=\text { jumlah lilitan } \\
\mu \mathrm{o}=\text { panjang } \text { Permeabilitas } & \mathrm{A}=\text { luas area }\left(\mathrm{m}^{2}\right) \\
(4 . \pi .10-7) & \\
l=\text { panjang koil dalam meter } &
\end{array}
$$
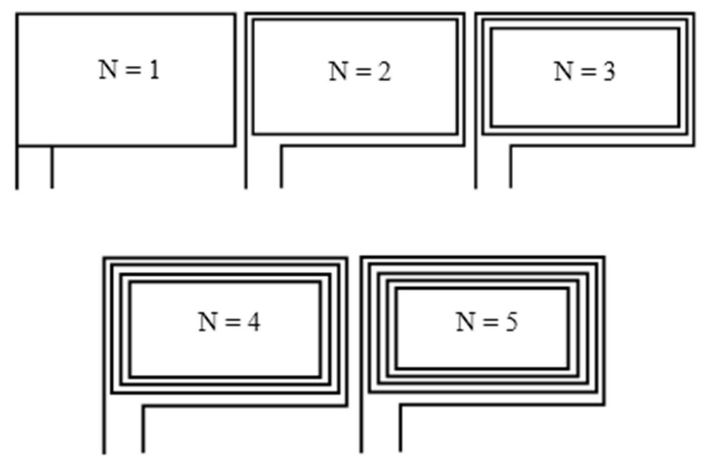

[12] Gambar 8. Jumlah belitan kawat loop detector
Hasil pengujian sensor loop detector dapat dilihat pada tabel berikut .

\section{[13] Tabel 4. Hasil Pengujian Sensor Loop Detector}

\begin{tabular}{ccccc}
\hline $\begin{array}{c}\text { Jumlah } \\
\text { Belitan }\end{array}$ & $\begin{array}{c}\text { Diameter/Luas } \\
\text { Sensor }\end{array}$ & $\begin{array}{c}\text { Luas } \\
\text { Objek }\end{array}$ & $\begin{array}{c}\text { Jarak } \\
\text { Maksimal }\end{array}$ & $\begin{array}{c}\text { Nilai } \\
\text { Induktansi }\end{array}$ \\
\hline 1 & & & $12.5 \mathrm{~cm}$ & $109.37 \mu \mathrm{H}$ \\
2 & & & $20.3 \mathrm{~cm}$ & $218.75 \mu \mathrm{H}$ \\
3 & $35 \mathrm{~cm} \times 50 \mathrm{~cm}$ & $28 \mathrm{~cm}$ & $24 \mathrm{~cm}$ & $328.12 \mu \mathrm{H}$ \\
4 & & & $27,5 \mathrm{~cm}$ & $437.5 \mu \mathrm{H}$ \\
5 & & & $30,7 \mathrm{~cm}$ & $546.87 \mu \mathrm{H}$ \\
\hline
\end{tabular}

Berdasarkan Tabel 4, dapat disimpulkan bahwa jika semakin banyak lilitan maka nilai induktansi akan semakin besar, dan juga panjang jarak yang mampu di baca oleh sensor semakin panjang, lalu untuk pengaplikasian sensor secara nyata dapat menggunakan 4 belitan dengan jarak maksimal pembacaan sensor setinggi $27.5 \mathrm{~cm}$, mengapa demikian karena pada umumnya ground clearance atau ruang antara dasar dari ban kendaraan dengan bagian paling bawah atau sasis pada sebuah mobil MPV rata-rata memiliki ketinggian setinggi $20 \mathrm{~cm}-22 \mathrm{~cm}$, dan mobil SUV setinggi $22 \mathrm{~cm}-$ $24 \mathrm{~cm}$, jadi agar sensor dapat membaca objek secara tepat dapat menggunakan 4 belitan dengan ketinggian pembacaan sensor maksimal $27 \mathrm{~cm}$

\section{Pengujian Monitoring}

Pengujian ini dilakukan untuk memantau kondisi slot parkir dengan keadaan online melalui server lokal, caranya yaitu dengan mengkoneksikan NodeMCU ESP8266 dengan device yang akan digunakan untuk memonitor menggunakan wireless. NodeMCU akan mencari wifi secara otomatis, setelah berhasil terkoneksi pada serial monitoring akan muncul alamat IP yang bisa diakses untuk memonitoring keadaan slot parkir, proses pencarian wifi seperti pada gambar berikut.

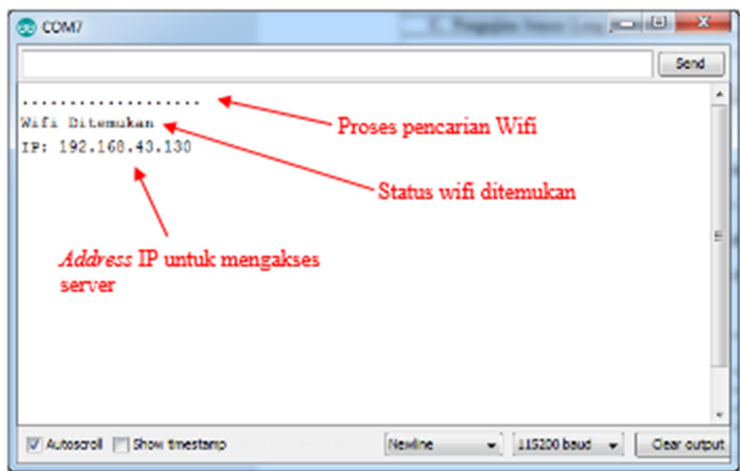

[14] Gambar 9. Proses pencarian wifi

Setelah NodeMCU terkoneksi dengan hotspot, selanjutnya ketersediaan slot parkir dan letak slot yang kosong dapat dimonitoring dengan mengetikan alamat IP Address yang telah 
terhubung, setelah masuk halaman awal dapat dilihat seperti gambar berikut.

\begin{tabular}{|c|c|}
\hline $\begin{array}{c}\text { SMART CAR PARKING } \\
\text { SYSTEM }\end{array}$ & $\begin{array}{c}\text { SMART CAR PARKING } \\
\text { SYSTEM }\end{array}$ \\
\hline SLOT 1: kosong & SLOT 1: Terisi \\
\hline SLOT 2: kosong & SLOT 2: kosong \\
\hline SLOT 3: kosong & SLOT 3: Terisi \\
\hline SLOT 4: kosong & SLOT 4: Terisi \\
\hline SLOT 5: kosong & SLOT 5: Terisi \\
\hline SLOT 6: kosong & SLOT 6: kosong \\
\hline SLOT ISI: 0 & SLOT ISI: 4 \\
\hline SLOT KOSONG: 6 & SLOT KOSONG: 2 \\
\hline
\end{tabular}

[15] Gambar 10. Tampilan web monitoring ketika kosong(kiri) dan ketika terisi (kanan)

\section{KESIMPULAN}

Dari hasil penelitian dan pembuatan prototipe sistem smart parking ini maka diperoleh kesimpulan sebagai berikut :

a. Prototipe sistem smart parking berbasis IoT Menggunakan NodeMCU ESP8266 ini telah berhasil dibuat dan telah dilakukan pengujian.

b. Sistem perhitungan dan penempatan slot parkir menggunakan kartu RFID dengan mengurutkan slot terkecil dan memilih slot kosong terkecil telah sesuai.

c. Petunjuk pengarahan slot parkir ditampilkan pada display berupa LED dotmatrix Modul P10.

d. Jumlah ketersediaan slot parkir dan letak slot parkir yang kosong dapat dilihat secara online dengan menggunakan web monitoring server lokal.

\section{DAfTAR Pustaka}

[1] Kristanto, A. (2019) 'Rancang Bangun Sistem Parkir Otomatis Pada Kampus Ii Itn Malang Menggunakan Minimum Sistem Arduino Dengan Website Sabagai Media Pelaporan', Jurnal Mahasiswa Teknik Informatika, 3(1), pp. 46-52.

[2] Winarsih, I. and Mahendra, R. (2009) 'Sistem Parkir Otomatis Menggunakan RFID Berbasiskan Mikrokontroler AT 89S51', JETri, 8, pp. 21-36.

[3] Yue, D., Wu, X., Hao., M., \& Bai, J. (2011). A Cost-Benefit Analysis for Applying RFID to Pharmaceutical Supply Chain. International Conference on Service System and Service Management (ICSSSM). 25-27 June 2011. Tianjin. China.

[4] Kumar, P., \& Pati, U.C. (2016). IoT Based Monitoring and Control of Appliances for Smart Home. IEEE International Conference On Recent Trends In Electronics Information Communication Technology. 20 - 21 Mey 2016, 1145 -1150. Bangalore. India.

[5] Hamdani, F. (2014) 'Penerapan Rfid ( Radio Frequency Identification ) Di Perpustakaan: Kelebihan Dan
Kekurangannya', Penerapan RFID (Radio Frequency Identification) di Perpustakaan: Kelebihan dan Kekurangan, 2(1), pp. 71-79.

[6] Prasetyo, W. A. et al. (2017) 'Pengelolaan sistem parkir dengan rfid berbasis arduino uno', pp. 1-14.

[7] Limantara, D. A. et al. (2017) 'Pemodelan Sistem Pelacakan LOT Parkir Kosong Berbasis Sensor Ultrasonic Dan Internet Of Things ( IOT ) Pada Lahan Parkir Diluar Jalan', Seminar Nasional Sains dan Teknologi, 1(2), pp. 1-10.

[8] Zulkarnain, D. and Julian, E. S. (2017) 'Perancangan Sistem Parkir Dengan Rekomendasi Lokasi Parkir', JETri Jurnal Ilmiah Teknik Elektro, 14(2), pp. 17-28. Available at: http://trijurnal.lemlit.trisakti.ac.id/index.php/jetri/article/view/1 611.

[9] Pambudi, S. A. (2007) 'Menggunakan Sensor Ldr Berbasis Mikrokontroler At89S51', pp. 1-5.

[10] Putra, D. I. et al. (2018) 'Sistem Cerdas Reservasi dan Pemantauan Parkir pada Lokasi Kampus Berbasis Konsep Internet of Things', Jurnal Teknologi dan Sistem Komputer, 6(2), pp. 57-63. doi: 10.14710/jtsiskom.6.2.2018.57-63. 